\title{
Efficacy of ebastine, cetirizine, and loratadine in histamine cutaneous challenges
}

\author{
Juan Gispert, MD*; Rosa Antonijoan, $\mathrm{PhD} \dagger$; Manel Barbanoj, $\mathrm{PhD \dagger}$; Ignaci Gich, $\mathrm{PhD} \dagger$;
} Estrella Garcia, PhD*; Ramon Esbrí, BSc*; and Xavier Luria, MD*

Background: Few studies have compared the antihistaminic effect of ebastine at $20 \mathrm{mg} /$ day (maximal recommended daily dose) with the effect found for other antihistamines in human pharmacologic models.

Objective: To compare the inhibition of the histamine-induced skin reaction produced by ebastine (20 mg/day) with that produced by cetirizine (10 mg/day), loratadine $(10 \mathrm{mg} /$ day $)$, or placebo in a double-blind, randomized, crossover, placebocontrolled clinical trial.

Methods: Twenty volunteers (10 men and 10 women) received the four treatments once daily for 7 days, with a mean 7 -day washout period between treatments. Three intradermal histamine challenges $(0.05 \mathrm{~mL}$ of a $100 \mu \mathrm{g} / \mathrm{mL}$ histamine solution at 4 , 8 , and 24 hours after drug administration) were performed at baseline, day 1 (single dose), and day 7 (multiple doses). Wheal and flare areas were measured after 15 minutes.

Results: All treatments yielded significant reductions of histamine-induced wheal in comparison to placebo $(P<0.001)$. Analysis of covariance revealed significant differences between treatments $(P<0.05)$. Ebastine had a significantly greater antihistaminic effect than did cetirizine or loratadine, except at 4 hours after a single dose versus cetirizine. Further, the effect of cetirizine was similar with single or multiple doses after both 4 and 24 hours, whereas the effect of ebastine showed significant increases in wheal reduction with multiple doses $(P<0.05)$. No serious adverse events or withdrawals occurred during the study.

Conclusion: This study shows that ebastine in a $20-\mathrm{mg}$ dose is an effective once-daily antihistamine. Superior efficacy was found in comparison to cetirizine $(10 \mathrm{mg})$ or loratadine $(10 \mathrm{mg})$ on the overall skin wheal response after single and multiple doses.

Ann Allergy Asthma Immunol 2002;89:259-264.

\section{INTRODUCTION}

Histamine is present in most tissues and, through its interaction with the $\mathrm{H}_{1}$ receptor, is one of the most important chemical mediators in the pathophysiologic process of the allergic response in both the early and the late phase. ${ }^{1}$ Histamine is involved in the development of allergic rhinoconjunctivitis, urticaria, and skin reactions attributable to insect bites and contact dermatitis.

Since the early $1980 \mathrm{~s}$, a second generation of $\mathrm{H}_{1}$ receptor antagonists has been marketed. The combination of potency and lack of effects on the central nervous system distinguishes these compounds from the first-generation agents. Further, their pharmacokinetic characteristics are similar: good or excellent oral absorption; maximal time between 0.5 and 4 hours preceding their maximal pharmacodynamic activity; prolonged elimination half-life; and linear pharmacokinetic dose-dependent relationship, with maximal clearance and area under the curve directly related to the administered dose. ${ }^{2}$

Several different methods have been proposed to compare the pharmacodynamic effects of antihistaminic drugs. The inhibition of histamine-induced wheal and flare is a useful technique for the comparison of $\mathrm{H}_{1}$ receptor antagonist drugs. Although all of them show a clear antihistaminic activity, they differ in

\footnotetext{
* Almirall Prodesfarma SA, Barcelona, Spain.

† Hospital de la Santa Creu i Sant Pau, Barcelona, Spain.

Received for publication September 25, 2001.

Accepted for publication in revised form October 23, 2001.
}

potency, time to peak effect, and duration of the effect. ${ }^{3}$ Further, the sensitivity, specificity, and reproducibility of this bioassay are excellent when it is performed in a standardized manner in healthy volunteers or in subjects with allergic disorders., ${ }^{4,5}$

Ebastine is the only second-generation $\mathrm{H}_{1}$ receptor antagonist with a recommended once-daily flexible dose (10 or 20 $\mathrm{mg}$ ), depending on the severity of the disease. Most reported studies have compared the antihistaminic effect of ebastine in a dosage of $10 \mathrm{mg}$ daily with the effect found for other antihistamines in human pharmacologic models. ${ }^{6-9}$ Scant data are available, however, about the maximal recommended dosage for ebastine-20 mg daily. Only two studies have reported the pharmacodynamic effect of ebastine at $20 \mathrm{mg}$ daily in comparison to that of cetirizine at $10 \mathrm{mg}$ daily. ${ }^{10,11}$ One of these studies was performed after 4 hours, ${ }^{10}$ whereas the other evaluated skin reactions after 24 hours of a steadystate treatment (6 days). ${ }^{11}$ In the current study, we compared the antihistaminic effect of ebastine administered at $20 \mathrm{mg}$ daily with that of cetirizine at $10 \mathrm{mg}$ daily, loratadine at 10 $\mathrm{mg}$ daily, or placebo during the first 24 hours after a single dose (1 day) and multiple doses ( 7 days).

\section{METHODS}

\section{Study Subjects}

The volunteer subjects were included in this study if they were healthy (according to the standard criteria included in the protocol), 18 to 50 years old, and Caucasian. They were subjected to extensive analysis of medical history and thor- 
ough physical examination, complete blood cell count, evaluation of hepatic and renal function, and electrocardiographic (ECG) study before inclusion. These procedures were repeated the first day of each treatment period. A histaminechallenge test was performed at selection, with use of the same methods as during the experimental phase. The subjects whose induced wheal and flare were more than or less than the mean value \pm 2 standard deviations of the general prescreened population were excluded from the study to have a homogeneous study cohort. The mean wheal area of excluded subjects was $157.3 \mathrm{~mm}^{2}$ (range, 55.2 to 259.4 ).

The main exclusion criteria were: pregnancy or breastfeeding in women or no proven oral contraceptive treatment or intrauterine device; any acute or chronic illness; intolerance to lactose; positive results for human immunodeficiency virus, hepatitis B surface antigen, or hepatitis C antibody; positive dermatographism; excessive ingestion of substances containing alcohol or xanthines; professional drivers; donation of blood during the month before the study; participation in another trial during the 3 months before the study; and any change in skin appearance during the study period. Overall, 20 healthy subjects (10 men and 10 women; mean age, $23.3 \pm 2.9$ years) were enrolled. The protocol was approved by the Clinical Research Ethics Committee of the Hospital de la Santa Creu i Sant Pau. Each volunteer gave written informed consent before inclusion, and the study was conducted according to established good clinical practice and national regulatory rules.

\section{Study Design}

This was a double-blind, randomized, crossover (Latin square design), placebo-controlled study. Eligible subjects were randomized to one of the following treatment sequences: $\mathrm{A} / \mathrm{B} /$ $\mathrm{C} / \mathrm{D}, \mathrm{B} / \mathrm{D} / \mathrm{A} / \mathrm{C}, \mathrm{C} / \mathrm{A} / \mathrm{D} / \mathrm{B}$, or $\mathrm{D} / \mathrm{C} / \mathrm{B} / \mathrm{A}$. All participants were instructed to go to the investigational center fasting to receive their daily dose (at $9 \mathrm{Am}$ ) during the 7 days of each treatment period. Every treatment was followed by a 7- to 15-day washout period, as recommended by the general principles for allergy diagnostic testing described by Bernstein and Storms. ${ }^{5}$ The double-blind design was achieved by including all the treatments studied - ebastine $(20 \mathrm{mg})$, loratadine $(10 \mathrm{mg})$, cetirizine $(10$ $\mathrm{mg}$ ), and lactose as placebo-in identical capsules. Study subjects were given one capsule orally every day together with 200 $\mathrm{mL}$ of water. Pharmaceutical tests were performed to ensure the validity of the blinding method.

\section{Skin Testing and Assessment of Efficacy}

Intradermal tests, with use of $0.05 \mathrm{~mL}$ from a solution containing $100 \mu \mathrm{g} / \mathrm{mL}$ of histamine, were performed on the volar surfaces of the forearms. The tests were separated by at least $2.5 \mathrm{~cm}$, and the sequences of the sites chosen were randomly located and identical for each study subject in single-dose and multiple-dose tests. Tests were performed at baseline and at 4,8 , and 24 hours after the single dose and the 7-day regimen.

The efficacy of treatments was evaluated by measuring the wheal and flare areas before treatment and at each aforemen- tioned time after treatment. Wheal and flare circumferences were traced and transferred to transparent paper 15 minutes after the test. Major and minor diameters were measured on a $90^{\circ}$ angle. The wheal and flare areas were calculated with use of the ellipse formula:

Area $=\pi \times$ maximal diameter $\times$ minimal diameter $/ 4$

in which $\pi=3.1416$.

Percentage suppression of the wheal and flare areas was calculated with use of the following equation:

$\%$ reduction $=100-($ surface after treatment

$\times 100 /$ basal surface)

\section{Assessment of Safety}

All adverse events experienced during the study were recorded. Further, at the end of each study period, ECG, hematologic studies, and urinalysis were performed.

\section{Statistical Analysis}

The 95\% confidence intervals (CI) were calculated for suppression of wheal and flare values at each designated time. The comparison between treatments was performed by using an analysis of covariance model with one factor (treatment) and with baseline values as covariant. Post hoc tests for comparisons of single-dose versus multiple-dose suppressions were corrected for multiple testing by using the Bonferroni method. Statistical significance was defined as $P$ values at the 0.05 level.

\section{RESULTS}

All 20 subjects completed the study, and all had normal values for clinical, analytical, and ECG tests performed before entering the study. Compliance with treatment was complete in all participants. Analysis of the baseline wheal surface showed no significant differences between the various preestablished sequences of treatment; thus, a first-order carryover effect was discarded.

\section{Efficacy}

The surface areas of the wheals induced after a single dose and after multiple doses ( 7 days) of treatment are shown in Table 1. The overall analysis of covariance model revealed significant differences between all active treatments and placebo $(P<0.0005)$. In Figures 1 and 2 , the percentage of wheal suppression $(95 \% \mathrm{CI})$ after single and multiple doses, respectively, is depicted. Ebastine and cetirizine showed similar responses, which were clearly superior to those of loratadine and placebo. Globally, wheal suppression was higher after multiple-dose than after single-dose treatment, although this reduction was more relevant after 4 and 8 hours of treatment. Nevertheless, the wheal suppression achieved at 24 hours was superior with ebastine (CI, 56.43 to $71.02 \%$ ) than with cetirizine (CI, 28.28 to $51.39 \%$ ). 
Table 1. Wheal Areas $\left(\mathrm{mm}^{2}\right)$, Stratified by Treatment Group and Time*

\begin{tabular}{ccrrr}
\hline Group & Baseline & $\mathbf{4} \mathbf{h}$ & $\mathbf{8} \mathbf{h}$ & $\mathbf{2 4} \mathbf{h}$ \\
\hline Single dose & & & & \\
Placebo & $174.7 \pm 28.3$ & $179.1 \pm 48.1$ & $182.0 \pm 47.2$ & $169.3 \pm 44.5$ \\
Ebastine & $184.1 \pm 45.6$ & $62.7 \pm 27.1$ & $51.8 \pm 28.7$ & $74.0 \pm 32.4$ \\
Cetirizine & $181.1 \pm 49.5$ & $43.9 \pm 17.9$ & $55.7 \pm 23.3$ & $104.2 \pm 30.5$ \\
Loratadine & $174.7 \pm 41.8$ & $122.1 \pm 30.2$ & $109.9 \pm 26.1$ & $136.9 \pm 41.6$ \\
Multiple dose & & & & \\
Placebo & & $162.7 \pm 42.1$ & $170.7 \pm 42.7$ & $182.5 \pm 30.0$ \\
Ebastine & & $45.9 \pm 22.6$ & $63.3 \pm 23.8$ \\
Cetirizine & & $46.9 \pm 16.5$ & 16.4 & $102.9 \pm 139.0$ \\
Loratadine & & $99.7 \pm 38.7$ & $114.2 \pm 36.9$ & $134.0 \pm 39.1$ \\
\hline
\end{tabular}

* Data are shown as mean \pm standard deviation.
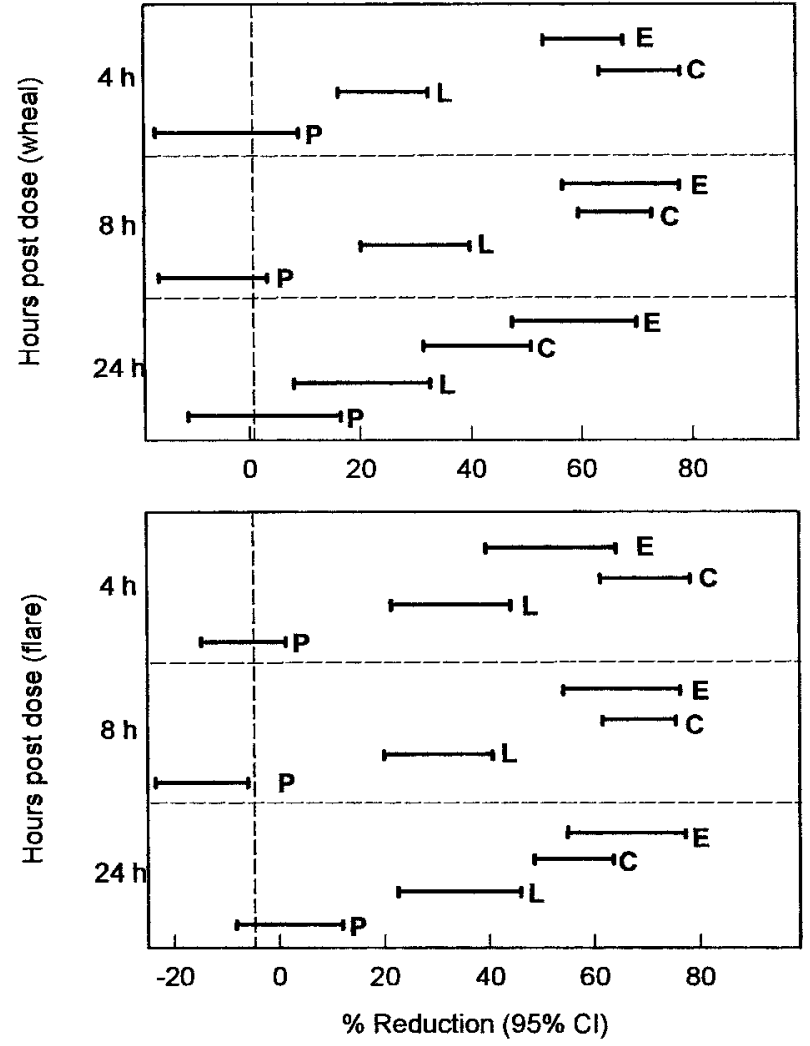

Figure 1. Percentage of suppression of induced wheal and flare after single-dose administration of various regimens. Data shown are the $95 \%$ CI. Histamine challenges were performed at 4,8 , and 24 hours after dose administration. $C$, cetirizine; $E$, ebastine; $L$, loratadine; $P$, placebo.

The wheal suppression found with loratadine was superior only to placebo, except for the 24-hour single-dose measurement (CI, 8.45 to $30.98 \%$ with loratadine; CI, -13.78 to $15.76 \%$ with placebo). The suppression of induced wheal by loratadine was a time-dependent result, both with a single dose (ranging from 19.7 to $36.6 \%, 25.8$ to $43.7 \%$, and 8.4 to $30.9 \%$ at 4,8 , and 24 hours, respectively) and with multiple doses (32.4 to $52.4 \%, 20.9$ to $43.7 \%$, and 8.3 to $32.0 \%$ ).
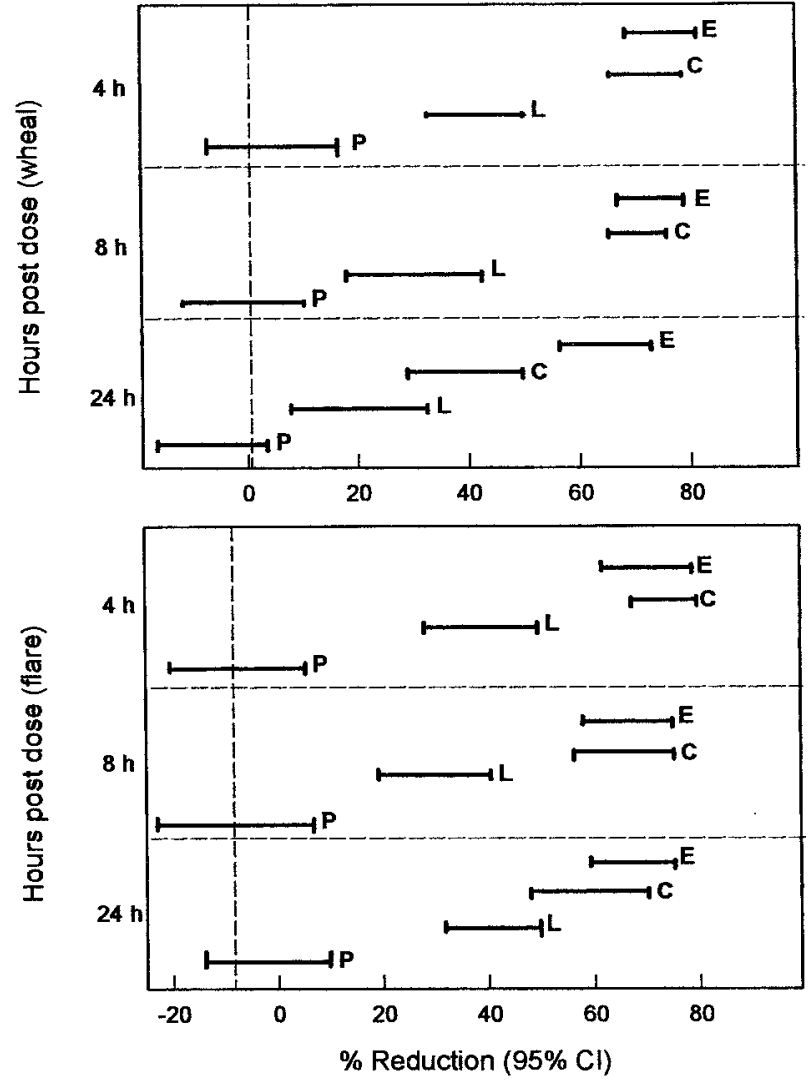

Figure 2. Percentage of suppression of induced wheal and flare after multiple-dose administration of various regimens ( 7 days of treatment). Data shown are the $95 \% \mathrm{CI}$. Histamine challenges were performed at 4,8 , and 24 hours after dose administration. $C$, cetirizine; $E$, ebastine; $L$, loratadine; $P$, placebo.

A comparison of the mean percentages of wheal suppression by the various treatment regimens and placebo is shown in Figure 3. The overall effect of treatment was significant $(P<0.001)$. Statistically significant differences $(P<0.05)$ were observed as follows: ebastine, cetirizine, and loratadine versus placebo; ebastine versus loratadine; ebastine versus cetirizine at 24 hours after single and multiple doses; and 


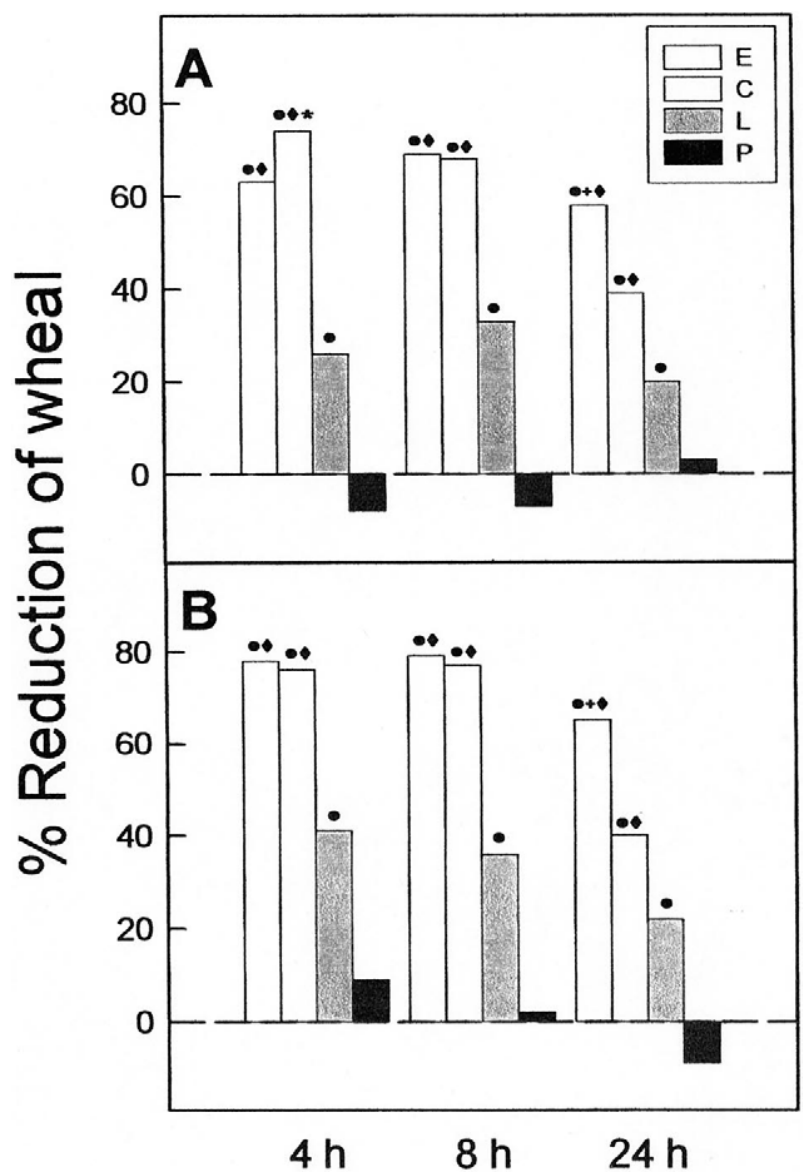

Figure 3. Comparison of the percentages of suppression of induced wheal between various treatments at 4,8 , and 24 hours. Data shown are mean values. $A$, Single dose (1 day). $B$, Multiple doses ( 7 days). Significant differences: $\bullet, P<0.05$ vs placebo $(P) ;+, P<0.05$ vs cetirizine $(C)$; $\diamond \diamond$, $P<0.05$ vs loratadine $(L)$; and $*, P<0.05$ cetirizine vs ebastine $(E)$. cetirizine versus loratadine. Cetirizine versus ebastine was significant only at 4 hours after a single dose.

The effect of ebastine increased significantly between single and multiple doses at 4 and 24 hours of treatment (Fig 4). A similar significant increase was also seen for loratadine at 4 hours of treatment (Fig 4), whereas no such differences were observed for cetirizine at any time studied.

Overall, the suppression of flare was comparable with the suppression of wheal by the various treatments (Figs 1 and 2).

Safety

No serious adverse events or withdrawals occurred during the study. Among the 20 study subjects, the most frequently reported adverse events were somnolence (in 6 subjects with cetirizine, 5 with ebastine, 4 with loratadine, and 1 with placebo) and headache (in 4 with cetirizine and 3 with loratadine, ebastine, and placebo, respectively). No clinical or statistically significant differences were found in the safety assessments: vital signs (systolic and diastolic blood pressure, heart rate, respiratory rate, and body temperature), blood studies, urinalysis, and ECG. Therefore, all treatments demonstrated cardiac safety. In particular, evaluation of the corrected QT interval demonstrated no alterations during any of the experimental periods.

\section{DISCUSSION}

The current double-blind, crossover, placebo-controlled study showed the overall greatest antihistaminic effect after a single dose with $20 \mathrm{mg}$ of ebastine. The only exception found was at the 4-hour point, where the highest effect was achieved with $10 \mathrm{mg}$ of cetirizine. Overall, these results correspond to those in previous studies. $3,8,9,12,13$ The difference at 4 hours between the pharmacodynamic effect of ebastine and cetirizine might be explained by the need for ebastine to be biotransformed into

\section{$\%$ Reduction of wheal}

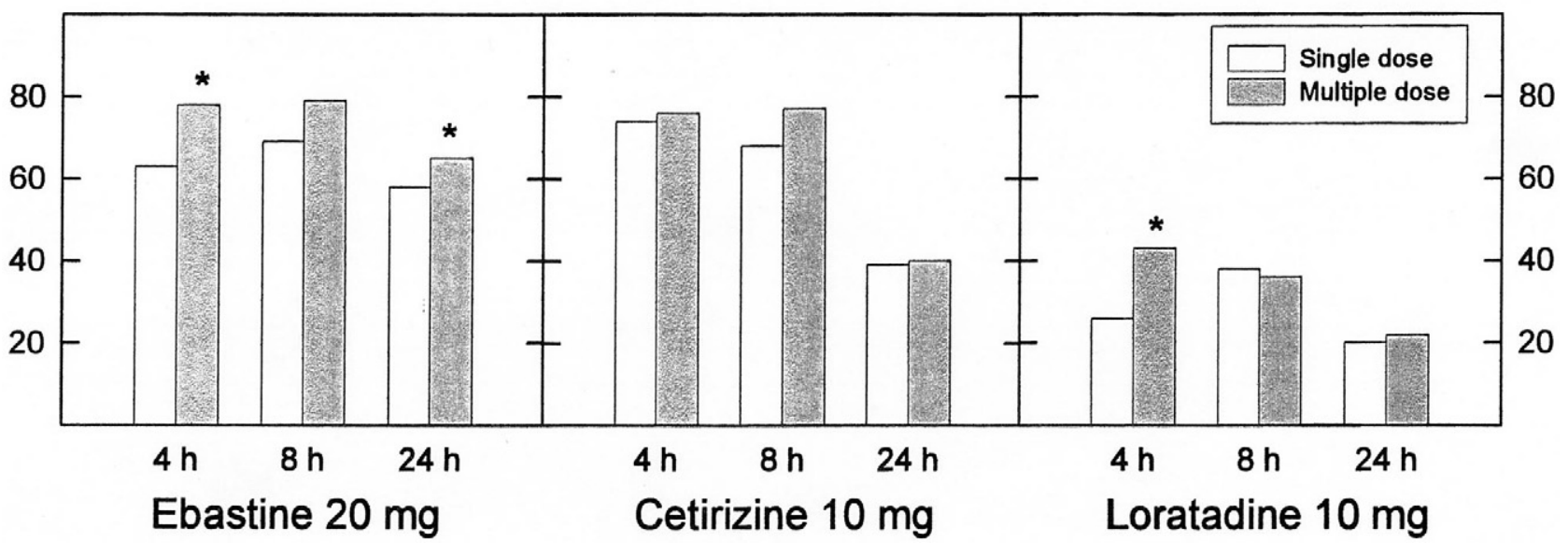

Figure 4. Comparison of activity between single and multiple doses of three drug regimens. Data shown are mean values. $*$, significantly different $(P<0.05)$ vs single dose. 
its active metabolite carebastine, ${ }^{14}$ whereas cetirizine is directly absorbed and active without biotransformation. ${ }^{13}$

Frossard et $\mathrm{al}^{8}$ compared the cutaneous dose-response to histamine challenge 4 hours after administration of $10 \mathrm{mg}$ of either cetirizine or ebastine; cetirizine was found to be more potent, with a lower variability of the inhibitory response. In the current study, however, the higher dose of ebastine (20 $\mathrm{mg}$ ) yielded a comparable intragroup variation with both treatments, as expressed by $95 \%$ CI. In fact, the histamine challenge we performed, using the intradermal test, is more sensitive and specific than the skin prick test used in this previous study ${ }^{4,5}$; thus, the reliability of the data obtained is good. Further, the effects of $20 \mathrm{mg}$ of ebastine and $10 \mathrm{mg}$ of cetirizine were significantly superior to placebo at all evaluation times.

Few studies have compared the pharmacodynamic effect of ebastine and cetirizine during a steady-state treatment. ${ }^{11} \mathrm{We}$ chose a 7-day treatment interval to obtain optimal steadystate conditions for the drugs studied..$^{13-15}$ The 24-hour delay after dosing was designed to compare the persisting effect of the once-daily second-generation antihistamine, although we also obtained data after 4 and 8 hours. We found that the effect of $20 \mathrm{mg}$ of ebastine was higher during steady-state conditions (achieved by multiple doses during 7 days of treatment) than the effect obtained with a single dose. In contradistinction, the effect of $10 \mathrm{mg}$ of cetirizine in multiple doses did not differ significantly from that achieved by a single dose. Further, a significantly higher wheal reduction was found with $20 \mathrm{mg}$ of ebastine than with $10 \mathrm{mg}$ of cetirizine after 24 hours of multiple doses. These results correlate with previous findings, in which the rank order of potency found in steady-state treatment after 24 hours of the last dose was $20 \mathrm{mg}$ of ebastine $>10 \mathrm{mg}$ of ebastine $>10 \mathrm{mg}$ of cetirizine $>$ placebo. ${ }^{11}$

The antihistaminic effect of loratadine in a 10-mg dose was significantly superior to placebo, but $10 \mathrm{mg}$ of loratadine proved the least potent inhibitor of both wheal and flare responses to histamine challenge in all measurements we performed (single or multiple doses). This lower activity of loratadine has been reported previously in other studies. ${ }^{7,9,12}$ Nevertheless, as found with ebastine, loratadine showed a significant improvement of antihistaminic effect after 4 hours with multiple dosing in comparison to a single dose. Although these values, even with this increase, were far inferior to those of ebastine or cetirizine, this fact needs further investigation because the implications in clinical practice could be relevant. Further, the duration of the antihistaminic effect found with ebastine was superior to that of the comparative drugs at 24 hours in both single-dose and multipledose tests. This finding could reflect a longer duration of its metabolite, carebastine, or a more prolonged capacity of binding to its receptor. Additional studies, however, are needed to clarify this point because the difference between elimination half-lives of the various study drugs and ebastinecarebastine is not so important. ${ }^{13-15}$
Pharmacodynamic models, such as that evaluated in this study, should not be interpreted as a direct measurement of clinical efficacy, because other chemical mediators have an important role in producing symptoms. ${ }^{16,17}$ Often, however, the suppression of histamine-induced wheal and flare correlates with alleviation of symptoms of allergic rhinitis. ${ }^{18-22}$ Therefore, it is still the recommended method for comparing $\mathrm{H}_{1}$ receptor antagonists. ${ }^{4}$ A sustained effect of $20 \mathrm{mg}$ of ebastine is beneficial, especially for those patients who are sensitive to indoor allergens or who may receive a continuous stimulus, as in the case of perennial allergic rhinitis. Studies involving allergic rhinitis indicate that a higher dosage of ebastine probably reduces the time needed to achieve a superior efficacy level, a factor that would probably improve the consistency of its efficacy. ${ }^{23,24}$

\section{CONCLUSION}

The results of this study indicate a superior efficacy of ebastine $(20 \mathrm{mg})$ in comparison to cetirizine $(10 \mathrm{mg})$ or loratadine (10 $\mathrm{mg}$ ) on the overall skin wheal response after single and multiple doses. Further, $20 \mathrm{mg}$ of ebastine was superior to placebo at all evaluation times. The current results substantiate previous pharmacodynamic findings and show ebastine in a 20 -mg dose as an effective once-daily antihistamine.

\section{REFERENCES}

1. Green JP, Prell GD, Khandelwal JK, Blandina P. Aspects of histamine metabolism. Agents Actions 1987;22:1-15.

2. Desager JP, Horsmans Y. Pharmacokinetic-pharmacodynamic relationships of $\mathrm{H}_{1}$-antihistamines. Clin Pharmacokinet 1995; 28:419-432.

3. DuBuske LM. Clinical comparison of histamine $\mathrm{H}_{1}$-receptor antagonist drugs. J Allergy Clin Immunol 1996;98:S307-S318.

4. Bousquet J, Michel FB. In vivo methods for study of allergy skin tests, techniques, and interpretation. In: Middleton E Jr, Reed CE, Ellis EF, et al, editors. Allergy: Principles and Practice. 4th ed. St Louis: Mosby-Year Book, 1993:573-594.

5. Bernstein IL, Storms WW. Practice parameters for allergy diagnostic testing. Joint Task Force on Practice Parameters for the Diagnosis and Treatment of Asthma. The American Academy of Allergy, Asthma and Immunology and the American College of Allergy, Asthma and Immunology. Ann Allergy Asthma Immunol 1995; 75:543-625.

6. Rivest J, Despontin K, Ghys L, et al. Pharmacological modulation by cetirizine and ebastine of the cutaneous reactivity to histamine. Dermatologica 1991;183:208-211.

7. Van Rooy P, Janssens M. Comparison of through effects of five non-sedating antihistamines on histamine-induced wheal and flare reactions. J Allergy Clin Immunol 1991;87:151.

8. Frossard N, Melac M, Benabdesselam O, Pauli G. Consistency of the efficacy of cetirizine and ebastine on skin reactivity. Ann Allergy Asthma Immunol 1998;80:61-65.

9. Grant JA, Danielson L, Rihoux JP, DeVos C. A double-blind, single-dose, crossover comparison of cetirizine, ebastine, epinastine, fexofenadine, terfenadine, and loratadine versus placebo: suppression of histamine-induced wheal and flare response for $24 \mathrm{~h}$ in healthy male subjects. Allergy 1999;54: $700-707$. 
10. Purohit A, Duvernelle C, Melac M, et al. Consistency and efficacy of cetirizine $(10 \mathrm{mg})$ versus ebastine $(20 \mathrm{mg})$ at $4 \mathrm{~h}$ on skin reactivity. Eur J Clin Pharmacol 1999;55:589-592.

11. Frossard N, Benabdesselam O, Purohit A, et al. Activity of ebastine (10 and $20 \mathrm{mg}$ ) and cetirizine at 24 hours of a steady state treatment in the skin of healthy volunteers. Fundam Clin Pharmacol 2000;14:409-413.

12. Simons FE, McMillan JL, Simons KJ. A double-blind, singledose, crossover comparison of cetirizine, terfenadine, loratadine, astemizole, and chlorpheniramine versus placebo: suppressive effects on histamine-induced wheals and flares during 24 hours in normal subjects. J Allergy Clin Immunol 1990;86: $540-547$.

13. Spencer CM, Faulds D, Peters DH. Cetirizine: a reappraisal of its pharmacological properties and therapeutic use in selected allergic disorders. Drugs 1993;46:1055-1080.

14. Wiseman LR, Faulds D. Ebastine: a review of its pharmacological properties and clinical efficacy in the treatment of allergic disorders. Drugs 1996;51:260-277.

15. Haria M, Fitton A, Peters DH. Loratadine: a reappraisal of its pharmacological properties and therapeutic use in allergic disorders. Drugs 1994;48:617-637.

16. Monroe EW, Daly AF, Shalhoub RF. Appraisal of the validity of histamine-induced wheal and flare to predict the clinical efficacy of antihistamines. J Allergy Clin Immunol 1997;99: S798-S806.

17. Baraniuk JN. Pathogenesis of allergic rhinitis. J Allergy Clin Immunol 1997;99:S763-S772.

18. Nelson HS, Rosloniec DM, McCall LI, Ikle D. Comparative performance of five commercial prick skin test devices. J Allergy Clin Immunol 1993;92:750-756.
19. Moreno Benitez F, Millan Núñez-Cortes J, Garcia Vadillo C, Lobaton Sanchez de Medina P. A study of the immediate cutaneous response: influencing factors. Allergol Immunopathol 1993;21:88-93.

20. Simons FE, Simons KJ. Peripheral $\mathrm{H}_{1}$-blockade effect of fexofenadine. Ann Allergy Asthma Immunol 1997;79:530-532.

21. Watson WT, Simons KJ, Chen XY, Simons FE. Cetirizine: a pharmacokinetic and pharmacodynamic evaluation in children with seasonal allergic rhinitis. J Allergy Clin Immunol 1989; 84:457-464.

22. Howarth PH, Emanuel MB, Holgate ST. Astemizole, a potent histamine $\mathrm{H}_{1}$-receptor antagonist: effect in allergic rhinoconjunctivitis, on antigen and histamine induced skin weal responses and relationship to serum levels. Br J Clin Pharmacol 1984;18:1-8.

23. Gehanno P, Bremard-Oury C, Zeisser P. Comparison of ebastine to cetirizine in seasonal allergic rhinitis in adults. Ann Allergy Asthma Immunol 1996;76:507-512.

24. Ratner PH, Lim JC, Georges GC. Comparison of once-daily ebastine $20 \mathrm{mg}$, ebastine $10 \mathrm{mg}$, loratadine $10 \mathrm{mg}$, and placebo in the treatment of seasonal allergic rhinitis. The Ebastine Study Group. J Allergy Clin Immunol 2000;105:1101-1107.

Requests for reprints should be addressed to:

Juan Gispert, MD

Almirall Prodesfarma S.A.

Cardener 68-74

08024 Barcelona, Spain

E-mail: jgispert@almirallprodesfarma.com 